\title{
Tartrazine induces structural and functional aberrations and genotoxic effects in vivo
}

\author{
Latifa Khayyat $^{1}$, Amina Essawy ${ }^{\text {Corresp.., }}{ }^{2}$, Jehan Sorour ${ }^{2}$, Ahmed Soffar ${ }^{2}$ \\ 1 Biology Department, Faculty of Applied Sciences, Umm Al-Qura University, Makkah, Saudi Arabia \\ 2 Zoology Department, Faculty of Science, Alexandria University, Alexandria, Egypt \\ Corresponding Author: Amina Essawy \\ Email address: amina_essawy@yahoo.com
}

Tartrazine is a synthetic organic azo dye widely used in food and pharmaceutical products. The current study aimed to evaluate the possible adverse effect of this coloring food additive on renal and hepatic structures and functions. Also, the genotoxic potential of tartrazine on white blood cells was investigated using comet assay. Twenty adult male Wistar rats were grouped into 2 groups of 10 each, control- and tartrazine-treated groups. The control group was administered orally with water alone. The experimental group was administered orally with tartrazine $(7.5 \mathrm{mg} / \mathrm{kg}$, b.wt.). Our results showed a marked increase in the levels of ALT, AST, ALP, urea, uric acid, creatinine, MDA and NO, and a decreased level of total antioxidants in the serum of rats dosed with tartrazine compared to controls. On the other hand, administration of tartrazine was associated with severe histopathological and cellular alterations of rat liver and kidney tissues and induced DNA damage in leucocytes as detected by comet assay. Taken together, the results showed that tartrazine intake may leads to an adverse health effects. 
1 Tartrazine induces structural and functional aberrations and genotoxic effects

2

3

7 Corresponding author: amina_essawy@yahoo.com

\section{Abstract:}

9 Tartrazine is a synthetic organic azo dye widely used in food and pharmaceutical products. The

\author{
Latifa I. Khayyat ${ }^{1}$, Amina E. Essawy ${ }^{2}$, Jehan M. Sorour ${ }^{2}$, Ahmed A.Soffar ${ }^{2}$
}

Biology Department, Faculty of Applied Sciences, Umm Al-Qura University, KSA ${ }^{1}$

,Zoology Department, Faculty of Science, Alexandria University, Moharam Bey ${ }^{2}$

Alexandria 2151, Egypt

\begin{abstract}
current study aimed to evaluate the possible adverse effect of this coloring food additive on renal
\end{abstract} and hepatic structures and functions. Also, the genotoxic potential of tartrazine on white blood cells was invertigated using comet assay. Twenty adult male Wistar rats were grouped into 2 groups of 10 each, control-and tartrazine-treated groups. The control group was administered orally with water alone. The experimental group was administered orally with tartrazine (7.5 $\mathrm{mg} / \mathrm{kg}$, b.wt.). Our results showed a marked increase in the levels of ALT, AST, ALP, urea, uric acid, creatinine, MDA and NO, and a decreased level of total antioxidants in the serum of rats dosed with tartrazine compared to controls. On the other hand, administration of tartrazine was associated with severe histopathological and cellular alterations of rat liver and kidney tissues and induced DNA damage in leucocytes as detected by comet assay. Taken together, the results showed that tartrazine intake may leads to an adverse health effects.

\section{in vivo}

\section{Introduction:}

22 Tartrazine (E number E102) a synthetic azo dye with lemon yellow color, is a commonly used

23 food colorant for food products that we eat almost every day (Mittal et al., 2007). Among foods 
24 including tatrazine are soft and sport drinks, flavored chips, sauces, ice creams, jams, jellies and chewing gums (Walton et al., 1999). Tartrazine is found in many non-food consumables such as soaps, cosmetics, shampoos, vitamins and certain prescription medications (Amin et al.,2010). Moreover, it is used in many developing countries as a low cost alternative for saffron in cooking (Mehediet et al., 2009).

Tartrazine toxicity results directly or indirectly from the metabolic reductive biotransformation of the azo linkadge (Chequer et al.,2011). For example, tartrazine can undergo metabolic reduction in the intestine of the animal by the intestinal microflora, thus resulting in formation of two metabolites, sulfanilic acid and aminopyrazolone (Chung et al., 1992). These metabolites of tartrazine can generate reactive oxygen species (ROS), generating oxidative stress, and affect hepatic and renal architectures and biochemical profiles (Himri et al., 2011).

Several in vivo studies have been administered tartrazine in different doses and revealed neither cytotoxic changes in tissues and organs nor development of neoplastic alteration in experimental animals (Rus et al., 2010).

Since literature data regarding the toxicity of tartrazine are contradictory, the present work aims to evaluate the toxic potential of tartrazine on livers and kidneys of male albino rats. In addition, this study was extended to evaluate the effect of this food colorant on the biomarkers of oxidative stress and to examine its genotoxic effect on white blood cells using comet assay.

\section{Materials and Methods:}

43 Twenty adult male Wistar albino rats of 146-153 g body weight were used in this study. They were kept under observation for about one week before the beginning of the experiment to exclude any underlying infection and to be allowed to acclimatize.

The animals were housed in cages and were maintained under controlled conditions of temperature $\left(24 \pm 2{ }^{\circ} \mathrm{C}\right)$ and light $(12: 12 \mathrm{~h}$ light:dark cycle). They received a standard basal diet (fat $5 \%$, carbohydrates $65 \%$, protein $20.3 \%$, fiber $5 \%$, salt mixture $3.7 \%$, vitamins mixture $1 \%$ ) and water ad libitum. The procedures of this experiment are compatible with the guide for care and use of laboratory animal approved by IACUC of Menoufia University, Egypt, Approval No:MNSP155.

52 Tartrazine (CAS 1934-21-0, Purity 86.7\%) was purchased from Sigma Aldrich (Germany). 


\section{Experimental design:}

54 The animals were randomly divided into 2 groups of 10 rats each.

55 Group 1: Animals were orally given distilled water $1 \mathrm{ml} / \mathrm{kg}$ b.wt. for 30 days and served as 56 controls.

57 Group 2: Animals were orally given tartrazine $7.5 \mathrm{mg} / \mathrm{kg}$ b.wt.(dissolved in $1 \mathrm{ml}$ of distilled 58 water) daily for 30 days (Himri et al., 2011).

59 After 30 days of treatment, animals from control and treated groups were fasted overnight, and 60 sacrificed under anesthesia. Blood samples were drawn from dorsal aorta into dry glass 61 centrifuge tubes and left to clot, then centrifuged at $3500 \mathrm{rpm}$ for $15 \mathrm{~min}$ in a Beckman Model T626 refrigerated centrifuge. Serum was separated and used for biochemical analysis.

63 Other blood samples were taken to isolate leucocytes for comet assay.

64 For histological and ultrastructure studies, small pieces of liver and kidney were quickly removed 65 and fixed in an appropriate fixative.

\section{Biochemical analysis:}

67 For biochemical analysis, serum was rapidly separated by centrifuging the clotted blood at $3000 \mathrm{~g}$ 68 for 10 min in a Beckman Model T-6 refrigerated centrifuge and collected into new clean and dry 69 tubes. Sera were stored at $-20{ }^{\circ} \mathrm{C}$ until assayed for the biochemical parameters. Aspartate aminotransferase (AST) and Alanine aminotransferase (ALT) were measured colorimetrically according to Steven (1996), while Alkaline phosphatase (ALP) activity was determined according to the method described by Mathieu (1980).

73 Creatinine, urea and uric acid were estimated using the methods of Henry (1974), Patton \& 74 Crouch (1977) and Caraway (1955), respectively.

75 Malondialdehyde (MDA), Nitric oxide (NO) and total antioxidant capacity (TAC) were estimated by the methods of Ohkawa et al. (1979), Cortas \& Wakid (1990) and Koracevic et al. (2001), respectively. They were determined using Bio-diagnostic assay kits according to the manufacturer's instructions (Giza, Egypt).

\section{Histological and ultrastructural study:}


80 After fixation of liver and kidney samples in Bouin's solution, they were dehydrated, cleared,

81 embedded in paraffin wax and then prepared for histological examination using hematoxylin and

82 eosin stain (Bancroft and Gamble, 2002).

83 For ultrastructural examination, small pieces of liver and kidney were immediately fixed in $4 \mathrm{~F} 1 \mathrm{G}$

84 in a phosphate buffer ( $\mathrm{pH} 7.2$ ) for 3 hours at $4{ }^{\circ} \mathrm{C}$, then post-fixed in $2 \% \mathrm{OsO}_{4}$ in the same buffer

85 at $4^{\circ} \mathrm{C}$ for $1-2$ hours. The specimens were dehydrated through a graded series of ethanol, 86 embedded in epon-araldite mixture and polymerized at $60^{\circ} \mathrm{C}$. Ultrathin sections $(50 \mathrm{~nm})$ from

87 selected areas were cut with glass knives on an LKB ultra microtome, double stained with uranyl

88 acetate and lead citrate and examined using a JEOL 100CX electron microscope.

\section{Genotoxicity study:}

90 Isolation of leucocytes for comet assay:

91 In order to isolate leucocytes, $4 \mathrm{ml}$ of fresh blood was collected in tubes containing 92 ethylenediaminetetraacetic acid (EDTA) as an anticoagulant. Blood samples were centrifuged at $9310000 \mathrm{rpm}$ for $5 \mathrm{~min}$. The white layer of leukocytes (buffy coat) was transferred to a new $2.0 \mathrm{ml}$ 94 microcentrifuge tube containing $2.0 \mathrm{ml}$ of cold freezing mixtures (RPMI 1640 with 10\% DMSO). 95 Aliquots of $250 \mu \mathrm{l}$ in $1.5 \mathrm{ml}$ microcentrifuge tubes were stored in a $-80^{\circ} \mathrm{C}$ freezer until comet 96 assay could be completed.

97 Comet assay:

98 Alkaline Comet assay was performed according to Collins (2004), with some modifications. The 99 comets were visualized by a fluorescence microscope (Zeiss Axioplan 2) equipped with an 100 Olympus C5050 camera. About 30 comets were scored and three different samples for each 101 group were examined. Percentage of DNA in the tail was determined by the Open Comet 102 software (Gyori et al., 2014).

\section{Statistical Analysis:}

104 The data of biochemical analysis and comet assay was expressed as mean \pm SD of 3-5 replicates 105 and were analyzed by one way ANOVA followed by student's $t$-test. The results are expressed as 106 mean \pm SD for three independent replicates. The difference was considered statistically 107 significant when $p<0.05$. 


\section{Results:}

109

110

111

112

113

114

115

116

117

\begin{tabular}{|l|c|c|c|}
\hline \multicolumn{1}{|c|}{ Group } & Control group & $\begin{array}{c}\text { Tartrazine-treated } \\
\text { group }\end{array}$ & $p$ value \\
Parameter & $48.40 \pm 4.26$ & $128.40 \pm 18.97$ & $0.003^{*}$ \\
\hline $\begin{array}{l}\text { Aspartate transaminase } \\
(\mathrm{U} / \mathrm{ml})\end{array}$ & $29.40 \pm 4.07$ & $71.20 \pm 7.75$ & $0.001^{*}$ \\
\hline $\begin{array}{l}\text { Alanine transaminase } \\
(\mathrm{U} / \mathrm{ml})\end{array}$ & $47.0 \pm 5.18$ & $89.40 \pm 6.66$ & $0.001^{*}$ \\
\hline $\begin{array}{l}\text { Alkaline phosphatase } \\
(\mathrm{U} / \mathrm{l})\end{array}$ & $0.36 \pm 0.07$ & $0.72 \pm 0.06$ & $0.004^{*}$ \\
\hline Creatinine $(\mathrm{mg} / \mathrm{dl})$ & $38.20 \pm 1.77$ & $46.0 \pm 2.12$ & $0.02^{*}$ \\
\hline Urea $(\mathrm{mg} / \mathrm{dl})$ & $0.59 \pm 0.07$ & $0.92 \pm 0.07$ & $0.009^{*}$ \\
\hline Uric acid $(\mathrm{mg} / \mathrm{dl})$ & $17.33 \pm 2.03$ & $46.67 \pm 5.61$ & $0.008^{*}$ \\
\hline Malondialdehyde(nM/ml) & $16.67 \pm 2.85$ & $41.0 \pm 3.79$ & $0.007^{*}$ \\
\hline Nitric oxide $(\mu \mathrm{M} / \mathrm{l})$ & $66.67 \pm 4.63$ & $28.33 \pm 4.06$ & $0.003^{*}$ \\
\hline Total antioxidants $(\mathrm{mM} / \mathrm{l})$ & & & \\
\hline
\end{tabular}

118

119

120

\section{Biochemical results:}

Table (1) shows that treatment with tartrazine resulted in a significant $(p<0.05)$ increase in the activity of plasma aspartate transaminase (AST), alanine transaminase (ALT) and alkaline phosphatase (AlP) compared to control. Also, our results showed a significant $(p<0.05)$ increase in plasma uric acid, urea and creatinine levels in tartrazine-treated animals. Additionally, rats exhibited a significant $(p<0.05)$ increase in plasma lipid peroxidation and nitric oxide $(\mathrm{NO})$, and a significant decrease in the total of antioxidants after treatment with tartrazine.

Table 1. Effect of tartrazine on serum biochemistry and oxidative biomarkers in male Wistar rats

\section{Data represented as mean $\pm \mathrm{SD}$.}

$p: \mathrm{p}$ value for $\mathrm{F}$ test (ANOVA) and significant between control and treated groups using Post Hoc Test (LSD) 
122 Light microscopic observations showed distortion of hepatic architecture in liver sections of 123 tartrazine-treated rats as compared to controls (Figs.1a-c). Most of hepatocytes appeared with 124 necrotic nuclei and cytoplasmic vacuolization. Some cells had irregular-shaped nuclei, while 125 others were devoid of nuclei (Fig.1c). Moreover, the blood sinusoids revealed dilatation and 126 congestion as well as white blood cell infiltration and Kupffer cells activation (Figs.1b\&c).

127 Electron microscope investigation revealed significant structural abbarations in liver and kidney 128 of tartrazine-treated rats. Nuclei ofhepatocytes appeared irregular or pyknotic and others 129 werewith less electron dense chromatin as compared to control (Figs.1d\&e). Alterations in the 130 lipid contents of cells were observed by the presence of numerous lipid droplets that vary insize 131 and shape (Fig.1e). Abnormal shaped mitochondria were observed with condensed opaque matrices and lack internal organization. The cisternae of rough endoplasmic reticulum appeared dilated and fragmented (Fig.1f). Rarefied areas in the cytoplasm could be resulting from dissociation of cellular organelles as well as scattered ribosomes that were also observed (Fig.1g). Moreover, obvious histological changes were observed in the structure of the kidney in the animal group treated with tartrazine when compared tocontrols (Figs.2a-c). These changes includes degeneration in glomerular structure, loss of renal tubules integrity andthe presence of areas of huge vacuoles (Fig.2b). Membrane injury in apical surfaces of tubular epithelial cells and degeneration in the basal membrane of cells were also noticed (Fig.2c).

140 Electron microscope investigation showed remarkable ultrastructural alterations in the kidney of rats treated with tartrazine. These changes includes degenerated proximal and distal tubular cells with nuclei containing clumps of marginated heterochromatin (Figs.2d\&f). Some of these nuclei appeared with irregular outline,while others were pyknotic. Vacuolated cytoplasm was a prominent feature in both proximal and distal tubular cells (Figs.2e\&g). Also, pleomorphic and disorganized mitochondria as well as increased number of lysosomes and Golgi vesicles were observed in proximal tubular cells (Fig.2h). In distal tubular cells, some mitochondria appeared normal while others were disrupted (Fig.2g). 

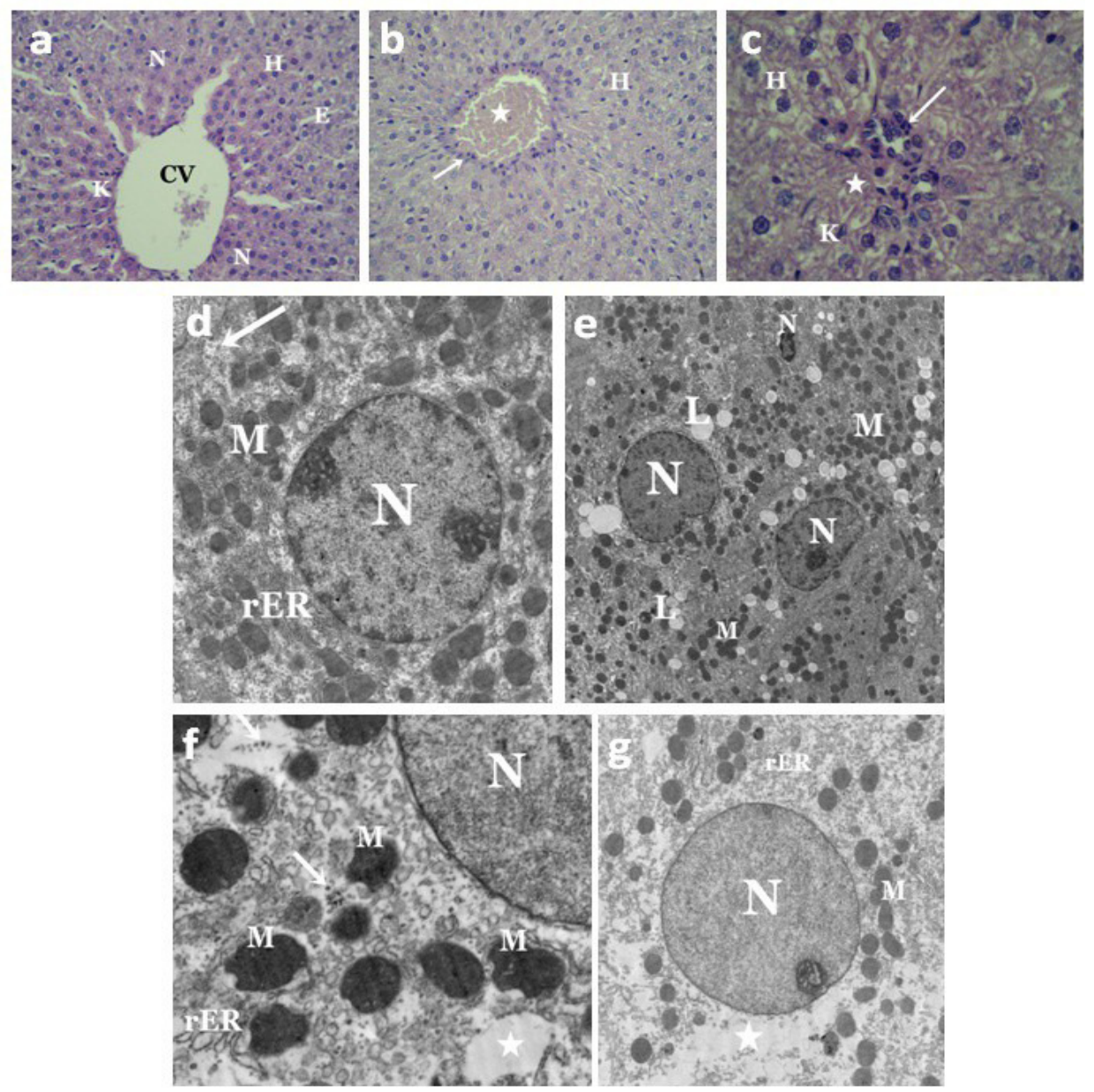

148 Fig.(1): (a-c) Light micrographs of liver sections from control and tartrazine-treated rats stained with $H \& E$ (a) Section from control rat showing hepatocytes $(H)$ with central spherical nucleus $(N)$, central vein (CV), endothelial cells (E) and Kupffer cells (K). X400. (b) Section from rat treated with tartrazine showing necrosis of most hepatocytes $(\mathrm{H})$, congestion of blood vessel (star) and leucocytic infiltration (arrow). X 400. (c) Section from rat treated with tartrazine showing vacuolated hepatocytes $(\mathrm{H})$, others devoid of nuclei (star), leucocytic infiltration (arrow) and Kupffer cells (K). X1000. (d-g) Electron micrographs of liver sections from control and tartrazine-treated rats. (d) Section from control rat, showing part of the hepatocyte with nucleus $(\mathrm{N})$, rough endoplasmic reticulum (rER), numerous mitochondria (M) and glycogen particles (arrows). X 2500. (e) Section from rat treated with tartrazine, showing irregular and pyknotic nuclei $(\mathrm{N})$, numerous lipid droplets $(\mathrm{L})$ and electron dense mitochondria (M). X1500. (f) Section from rat treated with tartrazine, showing abnormal shaped mitochondria (M), dilated rough endoplasmic reticulum cisternae (rER), scattered ribosomes (arrows) and clear area of cytoplasm (star). X4000. (g) Section from rat treated with tartrazine, showing less electron dense nucleus $(\mathrm{N})$, clear area of cytoplasm (star), electron dense mitochondria (M) and fragmented endoplasmic reticulum cisternae (rER). X2000. 

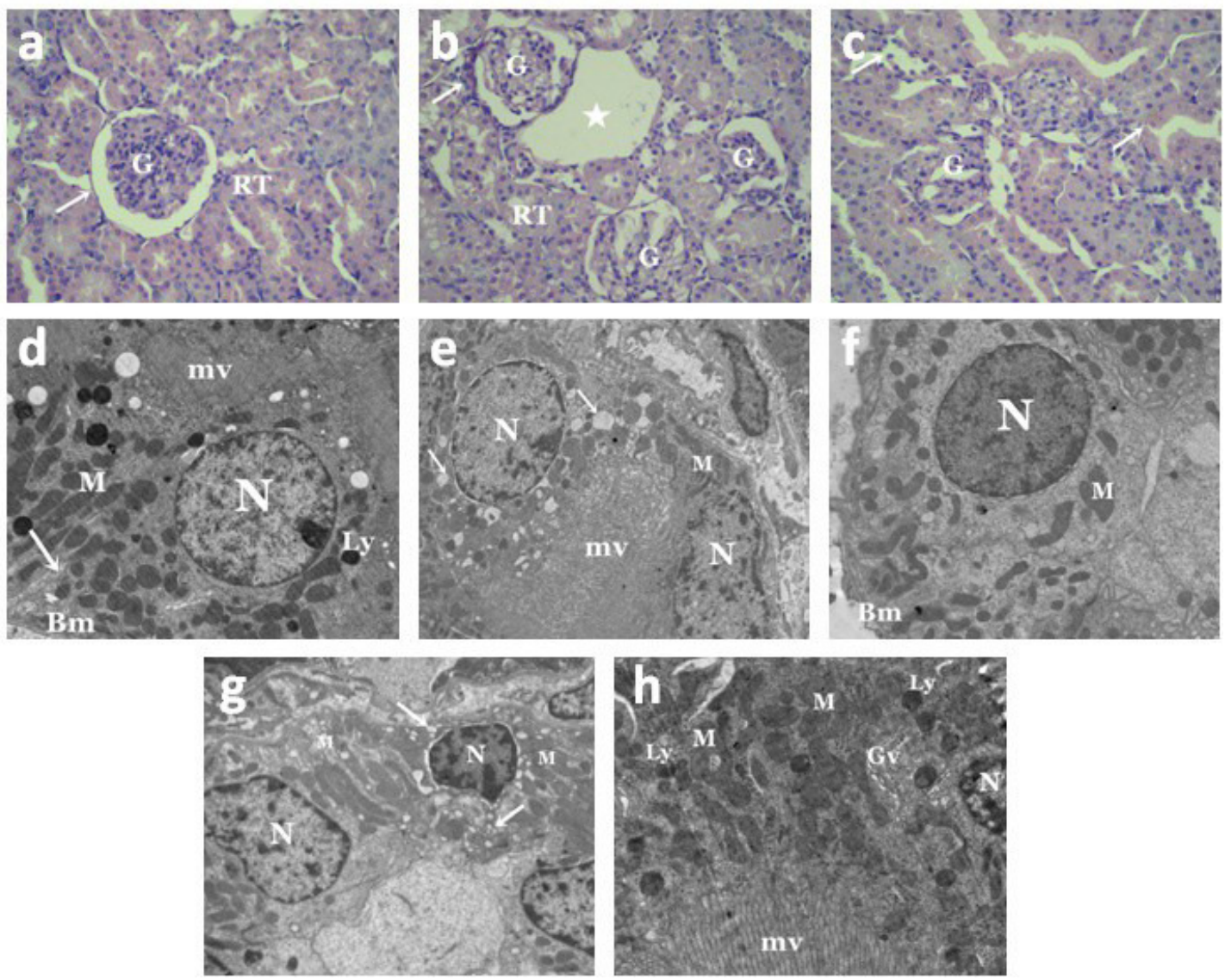

163 Fig. (2): (a-c) Light micrographs of kidney sections from control and tartrazine-treated rats stained with H\&E. (a) Section from control rat showing Malpighian corpuscles with its glomerulus (G), Bowman's capsule (arrow) and renal tubules (RT). X400. (b) Kidney section from rat treated with tartrazine showing degenerated glomeruli (G), loss of renal tubules integrity (RT), huge cavity with fragmented areas (star) and inflammation (arrow). X400. (c) Kidney section from rat treated with tartrazine showing damage in renal tubules membrane (arrows) and degenerated glomeruli (G). X400. (d-h) Electron micrographs of kidney sections from control and tartrazine-treated rats. (d) Kidney section from control rat showing proximal tubular cells with apical microvilli (mv), basement membrane (Bm), basal infoldings (arrow), nucleus (N), numerous mitochondria (M) and lysosomes (Ly). X2000. (e) Kidney section from rat treated with tartrazine showing disrupted proximal tubular cells with irregular nucleus $(\mathrm{N})$, vacuolated cytoplasm (arrows) and disordered mitochondria (M). X2000. (f) Kidney section from control rat showing distal tubular cell with nucleus (N), mitochondria (M) and basement membrane (Bm). X2000. (g) Kidney section from rat treated with tartrazine showing disrupted distal tubular cells with nucleus $(\mathrm{N})$, mitochondria (M) and vacuoles (arrows). X 2500.

(h) Enlarged part of proximal tubular cell from rat treated with tartrazine showing part of pyknotic nucleus $(\mathrm{N})$, destructed mitochondria $(\mathrm{M})$, numerous lysosomes (Ly), Gologi vesicles (Gv) and microvilli (mv). X4000.

\section{9}

\section{Genotoxicity results:}


180 Comet assay resulted that tartrazine possesses a genotoxic effect in the white blood cells of 181 treated rats (Figs.3a\&b). This genotoxic effect was observed as a significant increase $(p<0.05)$ in 182 the percentage of DNA in the comet tail in the nuclei of leucocytes of tartrazine-treated animals 183 as compared to controls.
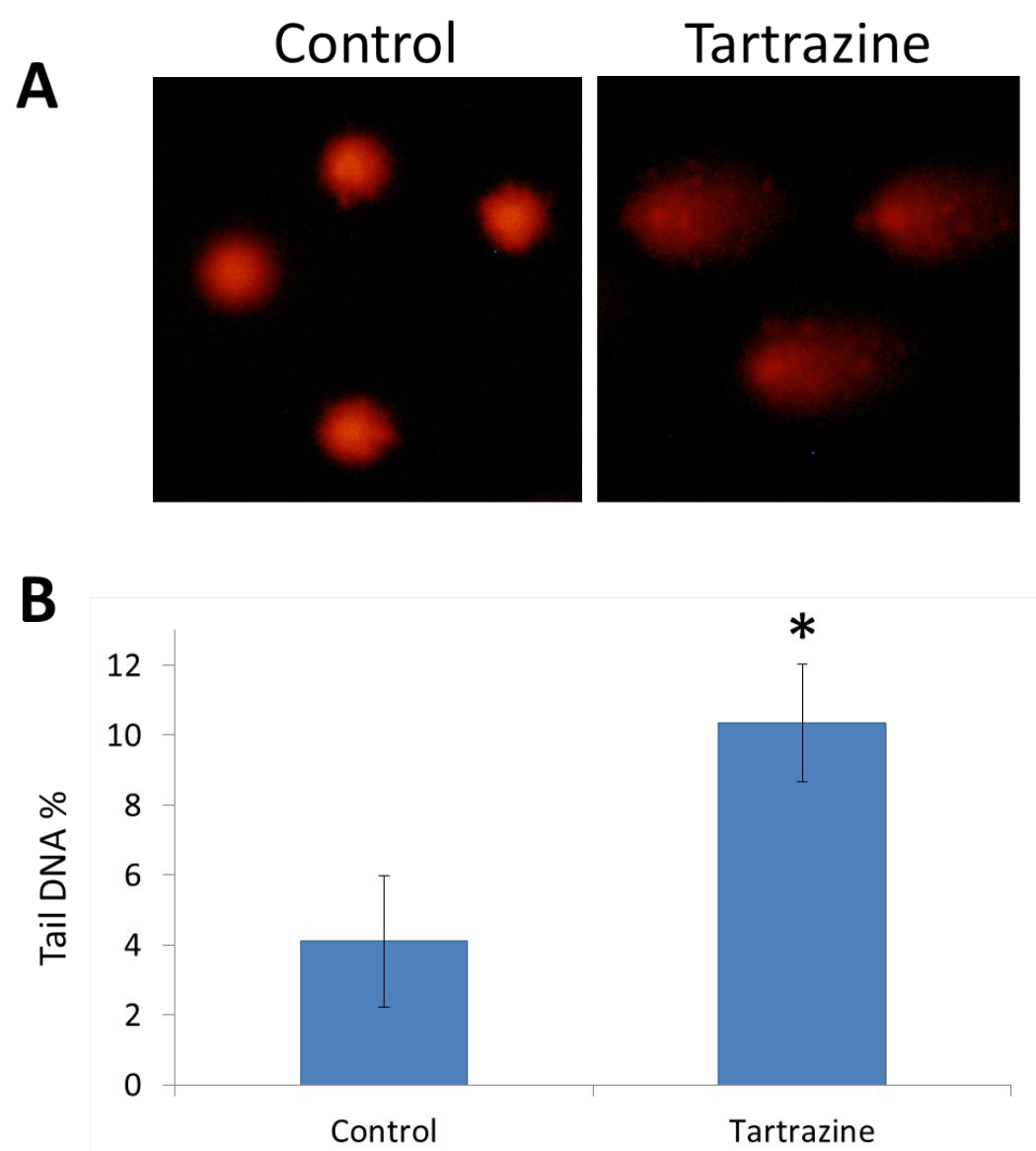

184 Fig. 3: The genotoxic effect of tartrazine on leucocytes of rats. (A) Fluorescence micrograph 185 representing nuclei of leucocytes after the comet assay. Control nuclei of untreated animals 186 appear intact with no detectable DNA damage. Nuclei of tartrazine-treated animals appear 187 damaged. (B) Bar graph showing the tail DNA damage in percentage in nuclei of leucocytes of 188 control and tartrazine-treated animals subjected to comet assay. Data are Mean $\pm \mathrm{SD}(\mathrm{n}=3, t$-test, $189 * p<0.05)$.

\section{Discussion:}

191 In the present work, adminstraiton of tartrazine significantly elevated the activity of serum ALT, 192 AST and ALP. The increased levels of liver enzyme activities in blood is an indication of a 193 possible tissue damage. These results are in accordance with data reported by other investigators 
194 who attributed similar changes in liver function to hepatocellular impairment. This liver damage 195 would releases greater than normal levels of intracellular enzymes into the blood (Amin et 196 al.,2010; Himri et al., 2011; El-Wahab \& Moram, 2015; Saxena \&, Sharma, 2015).

197 Serum levels of creatinine and urea are major factors in determination of both, the glomerular 198 filtration efficacy and proximal tubular secretion rate (Azu et al., 2010). Such damage in the the 199 filtering compartments of kidney, blood levels of creatinine and urea increase. Our results show a 200 significantly elevated serum levels of creatinine, urea and uric acidin tartrazine-treated group as 201 compared to controls. These results are in agreement with Tawfek et al. (2015) who found a 202 significant increase in serum creatinine and urea in rats following the consumption of different 203 types of food additives including tartrazine, sunset yellow and sodium benzoate. Similar finding 204 was observed by Ashour \& Abdelaziz (2009) in rats dosed with organic azo dye (fast green) orally 205 for 35 days. In addition, these results are in agreement with data reported by Amin et al. (2010) 206 who revealed a significant increase in serum creatinine and urea levels in rats after consumtion of 207 tartrazine. Recently, Nabila et al.(2013) mentioned that tartrazine application induced significant 208 elevations in urea and creatinine levels that is associalted with impared renal function and the 209 inability of the kidney to filter body fluids.

210 Oxidative stress is referred to a reactive oxygen species (ROS)/antioxidant imbalance. It occurs 211 when the overall level of ROS exceeds the potential of the antioxidants. Thus, oxidative stress 212 may occur because of accelerated ROS production, a drop of the antioxidant mechanisms, or both 213 (France's et al., 2013). In the present study, elevated levels of malondialdehyde (MDA, end 214 product of lipid peroxidation) and nitric oxide (NO) clearly indicates oxidative stress occurrence 215 in the tartrazine-treated rats. These results are in hand with data reported by Omaca et al. (2012) 216 who studied the oxidative effects of tartrazine and other azo dyes on chinese hamsters. The 217 increased lipid peroxidation may be attributed to the generation of ROS that result from tartrazine 218 administration. Because tartrazine belongs to the group of azo dye food colorants, it is 219 metabolized inside the body into aromatic amines by intestinal microflora. These formed amines 220 are able to generate ROS as part of their metabolism by the interaction of the active amino groups 221 with nitrite or nitrate containing foods (Moutinho et al., 2007). NO is considered as another 222 important source of free radicals that might contribute to alterations in energy metabolism. 223 Peresleni et al. (1996) demonstrated that oxidative stress to epithelial cells increases NO 224 syntheses which results in elevated NO release, nitrite production and decreased cell viability. 
225 The increased total tissue antioxidant capacity (TAC) provides a gross estimation of how the 226 body can react against oxidative stress (Constantini \& Verhulst, 2009). In the current work, the 227 decrease in the level of TAC in the serum of tartrazine-treated animals may be related to 228 increased free radical generation due to tartrazine administration and/or impaired antioxidant 229 machinary leading to increased oxidative stress.

230 Histological and ultrastructural results clearly showed that administration of tartrazine had led to 231 distortion of hepatic architecture as well as degeneration in kidney structure of rats. Light 232 microscopic figures showed tartrazine-induced necrosis of most hepatocytes, congestion of blood 233 sinusoids, infiltration of white blood cell, activated Kupffer cells, damaged glomerular and renal 234 tubule membranes. These findings are in agreement with Himri et al. (2011), Mehedi et al. (2013) 235 and Saxena \&, Sharma (2015) who indicated that tartrazine administration alters the histological 236 structure of livers and kidneys in experimental animals. Rus et al. (2010) found that tartrazine and 237 carmoisine causes congestion, stasis and edema in liver and kidney of Guinea pigs leading to 238 apoptosis in hepatocytes and atrophy of renal structures.

239 Several ultrastructural alterations were recorded in liver and kidney of rats treated with tartrazine. 240 The hepatocytes and renal tubule epithelium appeared with irregular or pyknotic nuclei. Large 241 numerous lipid droplets, disorganization of mitochondria, rough endoplasmic reticuli (rER) and 242 degenerated cytoplasmic areas were observed in the cytoplasm of hepatocytes. Meanwhile, 243 proximal and distal tubular cells possess vacuolated cytoplasm and defective mitochondria. These 244 results are similar to those of previous studies conducted with food additives, sodium benzoate 245 and citric acid (Bakar \& Aktac, 2014; Chen et al., 2014; Aktac et al., 2008; Kaboglu \& Aktac, 246 2002). The presence of pyknotic nuclei and necrosis of hepatocytes and tubular cells in the 247 current work clearly indicates toxicosis as previously described by Deveci et al. (2011) and 248 Sarkar and Ghosh (2012). Structural changes in nuclei and ER, the critical structures for 249 biosynthesis of glycoconjugates, could probably impairs glycosylation mechanisms and hence 250 affect cell surface sialylation (Bakar \& Aktac, 2014).

251 The increased amount of hepatocellular lipids was previously reported by Sinha and D'Souza 252 (2010) and Khidr et al. (2012) after sodium benzoate administration in experimental animals. 253 Cheville (1988) reported that toxins may affect ribosomes and their ability to produce peptide 254 chains and decreases the amount of proteins involved in the transport of triglycerides, that are 255 produced at their normal rates, causing accumulation of lipid globules. Deformation of 256 mitochondria and rER in hepatocytes and renal tubular cells cytoplasm after tartrazine 
257 administration could be a response to chemical stressors (Khidr et al. 2012). Reyes et al. (1996)

258 found that synthetic food coloring agents such as tartrazine, inhibited mitochondrial respiration in

259 liver and kidney of rats. It also affected the integrity of mitochondrial membranes, which is

260 critical for maintaining vital mitochondrial functions and determination of apoptosis in cells.

261 Bakar \& Aktac (2014) reported that degeneration of mitochondrial membranes and cristae

262 negatively affect oxidative metabolism of cells.

263 Our electron microscopic results showed a clear destruction of hepatocytic cytoplasm. Sinha \&

264 D'Souza (2010) reported that damage from toxic insults may cause swallowing of hepatocytes

265 with large clear spaces. The integrity of cytoplasm is important for regular intracellular

266 trafficking which in turn would be damaged due to cytoplasmic vacuolization (Bakar \& Aktac,

267 2014). The distortion of renal structures and tubular vacuolization found in the present work was

268 previously described by other workers in kidneys of animals treated with the food additive,

269 monosodium glutamate (Eweka, 2007; Abass \& Abd El-Haleem,2011; Afeefy et al., 2012).

270 Concerning the genotoxicity of synthetic colors, the obtained results revealed that tartrazine

271 caused DNA damage in leucocytes as detected by comet assay. This genotoxic effect is probably

272 due to the direct contact of tartrazine with nuclear DNA (Himri et al., 2012). Data pertaining to

273 the genotoxic effect of tartrazine with positive results are available. This finding agrees with

274 Mpountoukas et al. (2010) who investigated the toxic effect of tartrazine at 0.02-8 $\mathrm{mM}$ in human

275 peripheral blood cells in vitro. In addition, tartrazine has been shown to induce chromosomal

276 aberrations in fibroblast cells of Muntiacus muntjac (Chung et al., 1981). Hassan et al. (2010)

277 also revealed that adminatration of a daily dose of tartrazine ( 7.5 and $15 \mathrm{mg} / \mathrm{kg}$ b.wt.) for 7 weeks

278 leads to liver and kidney DNA damage.

279 On the contrary, a study carried out by Poul et al.(2009) showed that acute oral administration of 280 tartrazine did not induce genotoxic alterations in the micronucleus gut assay in mice at doses up 281 to $2 \mathrm{~g} / \mathrm{kg}$ b.wt. On the other hand, induction of tartrazine-induced DNA damage in comet assays 282 was observed in cells from the colon of mice (Sasaki et al., 2002) at a dose that is slightly higher 283 than the recommended human daily intake approved by the Joint FAO/WHO Expert Committee 284 on Food Additives (MHW, 1999). Therefore, further comet assay investigations performed 285 according to the latest recommended protocol (Hartmannet al., 2003) might be useful to clarify 286 these discrepancies. 
287 According to the above-discussed results, it can be concluded that tartrazine is able to generate 288 ROS thus accelerating oxidative stress, altering the structure and biochemical profiles in hepatic 289 and renal tissues. Therefore, controlling the consumption of tartrazine is important for the health 290 and limiting the use of tartrazine, especially in foods used by children, is highly advisable.

\section{References:}

292 Abass MA, Abd El-Haleem MR. 2011. Evaluation of monosodium glutamate 293 inducedneurotoxicity and nephrotoxicity in adult male albino rats. J. Am. Sci. 7,8 ,264-76.

294 Afeefy A, Mahmoud M, Arafa M. 2012. Effect of honey on monosodium glutamate induced 295 nephrotoxicity (Histological and electron microscopic studies). J. Am. Sci. 8,1s,146-156.

296 Aktac T, Kaboglu A, Kizilay G, Bakar E. 2008. The short-term effects of single toxic citric acid 297 doses on mouse tissues - Histopathological study.Fresen. Environ. Bull.17, 311-315.

298 Amin KA, Abdel Hameid H, AbdElsttar AH. 2010. Effect of food azo dyes tartrazine and 299 carmoisine on biochemical parameters related to renal, hepatic function and oxidative stress 300 biomarkers in young male rats. Food Chem.Toxicol. 48(10):2994-2999.

301 Ashour AA, Abdelaziz I. 2009. Role of fast green on the blood of rats and the therapeutic action 302 of vitamins C or E. Int. J. Integr. Biol.2009; 6 (1): 6-11.

303 Azu O, Francis I, Abraham A, Crescie C, Stephen O, Abayomi O. 2010. Protective agent, Kigelia 304 Africana fruit extract, against cisplatin-induced kidney oxidant injury in Sprague-Dawley rats. 305 Asian J. Pharm. Clin. Res., 3: 84-88.

306 Bakar E, Aktac T.2014. Effects of sodium benzoate and citric acid on serum, liver and kidney 307 tissue total sialic acid levels: An ultrastructural study. J.App.Bio.Sci.8 ,2, 9-15.

308 Bancroft J, Gamble M. 2002. Theory \& practice of histological technique. 5thed. N.Y: Churchill 309 Livingstone.p.796.

310 Caraway W.1955. Determination of uric acid in serum by carbonate method. Am J Clin Pat, 25: $311840-845$.

312 Chen, X.; Qiongxia, Lv.; Liu,Y. and Deng,W. (2014) : Study on injury effect of food additive 313 citric acid on liver tissue in mice. Cytotech., 66(2) 275-282. 
314 Chequer F, Dorta D, de Oliveira D.2011. Azo dyes and their metabolites: does the discharge of 315 the azo dye into water bodies represent human and ecological risks? In: Hauser PJ (ed) Advances 316 in treating textile effluent. In Tech, Croatia, pp 28-48.

317 Cheville N F. 1988. Introduction to Veterinary Pathology. Iowa State University Press, Ames, 318 IA.537.

319 Chung, K.T., Fulk, E.G., Andrews, A.W., 1981. Mutagenicity testing of some commonly used 320 dyes. Appl. Environ. Microbiol. 42, 641-648

321 Chung KT, Stevens JR, Cerniglia CE. 1992. The reduction of dyes by the intestinal microflora. 322 Crit. Rev. Microbiol. 18 (3), 175-190.Collins R. 2004. The comet assay for DNA damage and 323 repair: principles, applications, and limitations. Molecular Biotechnology, 26(3): 249-261.

324 Costantini D, Verhulst S. 2009. Does high antioxidant capacity indicate low oxidative stress? 325 Functional Ecology, 23, 506-509.

326 Cortas N, Wakid N.1990. Determination of inorganic nitrate in serum and urine by a kinetic 327 cadmium-reduction method. Clin Chem; 36(8 Pt 1):1440-1443.

328 Deveci E, Söker S, Baran Ö,Tunik S, Ayaz E, Deveci .2011. Ultrastructural changes in the kidney 329 cortex of rats treated with lead acetate. J. Morphol.29, 3,1058-1061.

330 El-Wahab HM, Moram GS.2015. Toxic effects of some synthetic food colorants and/or flavor 331 additives on male rats. Toxicol Int., 22(1): 152-157.

332 Eweka AO. 2007. Histological studies of theeffects of monosodium glutamate on the kidney 333 ofadult Wistar rats. The Internet Journal of Health. 6,2,45-67.

334 France's DE, Ingaramo PI, Ronco MT, Carnovale CE. 2013. Diabetes, an inflammatory process: 335 oxidative stress and TNF-alpha involved in hepatic complication. J. Biomed. Sci. Eng. 6, 645$336 \quad 653$

337 Gyori, B.M.; Venkatachalam, G.; Thiagarajan, P.S.; Hsu, D.; Clement, M.V.(2014): OpenComet: 338 An automated tool for comet assay image analysis. Redox Biol., 2: 457-65.

339 Hassan, G., (2010): Effects of some synthetic coloring additives on DNA damage and 340 chromosomal aberrations of rats. Arab J. Biotech., 13(1): 13-24. 
341 Hartmann A, Agurell E, Beevers C, Brendler-Schwaab S, Burlinson B, Clay P, Collins A, Smith 342 A, Speit G, Thybaud V, Tice RR.2003. Recommendations for conducting the in vivo alkaline 343 comet assay. Mutagenesis, 18, 45-51.

344 Henry R. 1974. Creatinine Measurements With Colorimetric Method. Clin. Chem. 345 Principles and Techniques. Harper \& Row Publishers.

346 Himri I, Bellahcen S, Souna F, BelmakkiF, Aziz M, Bnouham M, Zoheir J, Berkia Z, Aziz 347 M, Saalaoui E. 2011. A 90-day oral toxicity study of tartrazine, a synthetic food dye, in wistar 348 rats. Int J Pharm Sci.; 31 (3):159-169.

349 Himri I, Souna F, Aziz M, Hakkou A, Saalaoui E. 2012. DNA Damage Induced by Tartrazine in 350 rat whole blood using Comet Assay (Single Cell Gel Electrophoresis). Advances in 351 Environmental Biology, 6(11): 2875-2881.

352 Kaboglu A, Aktac T.2002. A study of the effects of sodium benzoate on the mouse 353 liver.Biologia. 57, 375-382.

354 Khidr B, Makhlouf M, Ahmed S.2012. Histological and ultrastructural study on the effect of 355 sodiumbenzoate on the liver of adult male albino rats. Assiut Univ. J. of Zool. 41,1,11-39.

356 Koracevic D, Koracevic G, Djordjevic V, Andrejevic S, Cosic V. 2001. Method for the 357 measurement of antioxidant activity in human fluids. J Clin Pathol, 54: 356-61.

358 Mathieu, M.(1980): In the scientific information Biologist. Soc Francaise Bid Clin, 2(8): 45

359 Mehedi N, Mokrane N, Alami O.,Ainad-Tabet S, Zaoui C, Kheroua O, Saidi D. 2013. A thirteen 360 week ad libitum administration toxicity study of tartrazine in Swiss mice. Afr. J. Biotechnol. 361 12,28, 4519-4529.

362 Mehedi N, Ainad-Tabet S, Mokrane N, Addou S, Zaoui C, Kheroua O, Saidi D. 2009. 363 Reproductive Toxicology of Tartrazine (FD and C Yellow No. 5) in Swiss Albino Mice. American 364 Journal of Pharmacology and Toxicology, 4(4): 128-133.

365 Ministry of Health and Welfare (MHW) of Japan (1999): The Japan's Specification and Standards 366 for Food Additives, 7th edn. Japan Food Additives Association, Tokyo 
367 Mittal A, Kurup L, Mittal J. 2007. Freundlich and langmuir adsorption isotherms and kinetics for 368 the removal of tartrazine from aqueous solutions using hen feathers. J Hazard Mater. 2007; 146(1369 2):243-248.

370 Moutinho I, Bertges L, Assis R. 2007. Prolonged use of the food dye tartrazine (FD\&C Yellown 371 degrees 5) and its effects on the gastric mucosa of Wistar rats. Brazilian Journal of Biology, 372 67(1): 141-145.

373 Mpountoukas P, Pantazaki A, Kostareli E, Christodoulou P, Kareli D, Poliliou S, Mourelatos C, 374 Lambropoulou V. 2010. Theodore Lialiaris. Cytogenetic evaluation and DNA interaction studies 375 of the food colorants amaranth, erythrosine and tartrazine. Food and Chemical Toxicology, 48: $376 \quad 2934-2944$.

377 Nabila M, Mokrane N, Alami O, TabetS, Zaoui C, Kheroua O, Saidi D. 2013. A thirteen week 378 ad libitum administration toxicity study of tartrazine in Swiss mice. African Journal of 379 Biotechnology, 12(28): 4519-4529.

380 Ohkawa H, Ohishi N,Yagi K. 1979. Assay for lipid peroxides in animal tissues by thiobarbituric 381 acid reaction. Anal Biochem, 95: 351-58.

382 Omca D, Zhang X, Ercal N. 2012. Oxidative effects of Tartrazine (CAS No. 1934-21-0) and 383 New Coccin (CAS No. 2611-82-7) azo dyes on CHO cells. J. Verbr. Lebensm. (2012) 7:229-236.

384 Patton C, Crouch S. 1977. Spectrophotometric and kinetics investigation of the Berthelot 385 reaction for the determination of ammonia. Anal. Chem., 49, 464-468.

386 Peresleni T, Noiri E, Bahou W, Goligorsky M. 1996. Anti sense oligodeoxynucleotides to 387 inducible NO synthase rescue epithelial cells from oxidative stress injury. Am J Physiol. 270(6): $388971-977$.

389 Poul M, Jarry G, Ould Elhkim M, Poul JM. 2009. Lack of genotoxic effect of food dyes 390 amaranth, sunset yellow and tartrazine and their metabolites in the gut micronucleus assay in 391 mice. Food and Chemical Toxicology,47 (2) : 443-448

392 Reyes FG, Valim MF, Vercesi AE. 1996. Effect of organic synthetic food colours on 393 mitochondrial respiration. Food Addit.Contam.13 (1): 5-11.

394 Rus V, Gherman C, Miclăuş V, Mihalca A, Nadăş G. 2010. Comparative toxicity of food dyes on 395 liver and kidney in guinea pigs:A histopathological study.Annals of RSCB.15,1,161- 165. 
396 Sarkar R, Ghosh AR.2012. Metanil Yellow-an azo dye induced histopathological and 397 ultrastructural changes in albino rat (Rattusnorvegicus). The Bioscan.7, 3, 427-432

398 Saxena B, Sharma S.2015. Food Color Induced Hepatotoxicity in Swiss Albino Rats, Rattus 399 norvegicus. Toxicol Int. 22(1):152-7. doi: 10.4103/0971-6580.172286.

400 Sasaki Y, Kawaguchi S, Kamaya A, Ohshima M, Kabasawa K, Iwam K, Taniguchi K, Tsuda 401 S.2002. The comet assay with 8 mouse organs: Results with 39 currently used food additives. 402 Mutat. Res., 519: 103 - 119.

403 Sinha R, D’Souza D. 2010. Liver cell damage caused due to sodium benzoatetoxicity in mice. 404 International J.Biotech.Biochem.6, 4, 549-554.

405 Steven CK. 1996. Alanine and Aspartat aminotransferase, principle and usage. In liver function, 406 In clinical chemistry theory, analysis and correlation. James J.T., Jenifer R.eds.M.Mosby, London $407 \quad 3^{\text {rd }}$ ed. 504-527.

408 Tawfek N, Amin H, Abdalla A, Fargali S.2015. Adverse Effects of Some Food Additives in Adult 409 Male Albino Rats. Current Science International, 4 (4); 525-537.

410 Walton K, Walker R, Sandt J, Castell J. 1999. The application of in vitro data in the derivation of 411 the acceptable daily intake of food additives. Food Chem. Toxicol. 37 (12), 1175-1197. 